\title{
FORMAÇÃO DO ENFERMEIRO PARA A ATENÇÃO BÁSICA: UM OLHAR SOBRE O CONHECIMENTO PRODUZIDO
}

TRAINING OF NURSES FOR PRIMARY HEALTH CARE: A LOOK AT THE KNOWLEDGE PRODUCED

FORMACIÓN DE LAS ENFERMERAS DE ATENCIÓN PRIMARIA DE SALUD: UNA MIRADA A LOS

CONOCIMIENTOS PRODUCIDOS

Maria da Conceição Coelho Brito ${ }^{1}$

Fiama Kécia Silveira Teófilo 2

Maria Socorro de Araújo Dias ${ }^{3}$

Maristela Inês Osawa Vasconcelos 4

Izabelle Mont'Alverne Napoleão Albuquerque ${ }^{5}$

Lielma Carla Chagas da Silva 6

\section{RESUMO}

0 desafio contemporâneo do setor educacional é formar cidadãos competentes no encontro de soluções para as situações cotidianas. Objetiva-se analisar a produção científica brasileira sobre a formação do enfermeiro para Atenção Básica, na base de dados Lilacs, entre os anos de 2005 e 2013. Revisão bibliográfica da literatura, realizada com a questão norteadora: 0 que as produções científicas brasileiras vêm abordando sobre a formação do enfermeiro para a Atenção Básica? A busca foi realizada com os descritores "Currículo" e "Educação em Enfermagem", sendo identificados 173 artigos, dos quais 24 foram selecionados. Verificaram-se os movimentos de mudanças instituídos na formação do enfermeiro, o currículo de enfermagem como um reflexo do dinamismo social, e os desafios para a implantação do novo currículo. Contudo, a atuação compromissada dos diversos atores possibilita a formação do enfermeiro coerente com as necessidades de saúde da população.

Palavras-chave: Enfermagem; Currículo; Ensino Superior; Formação de Recursos Humanos.

\footnotetext{
1. Enfermeira. Doutoranda em Cuidados Clínicos em Enfermagem e Saúde da Universidade Estadual do Ceará (UECE). Sobral (CE), Brasil.

2. Enfermeira. Mestranda em Saúde Coletiva da UECE. Fortaleza (CE), Brasil.

3. Enfermeira. Pós-doutorado em Cuidados Clínicos em Enfermagem e Saúde pela UECE. Docente do Curso de Enfermagem da Universidade Estadual Vale do Acaraú (UVA). Sobral (CE), Brasil.

4. Enfermeira. Pós-doutorado em Cuidados Clínicos em Enfermagem e Saúde pela UECE. Docente do Curso de Enfermagem da UVA. Sobral (CE), Brasil.

5. Enfermeira. Doutora em Enfermagem pela Universidade Federal do Ceará (UFC). Docente do Curso de Enfermagem da UVA. Sobral (CE), Brasil.

6. Enfermeira. Mestre em Saúde da Família pela UFC. Sobral (CE), Brasil.
} 


\section{ABSTRACT}

The contemporary challenge of the education sector is to train competent citizens to find solutions to everyday situations. The objective of this study was to analyze the Brazilian scientific production on the training of nurses for Basic Care in the Lilacs database between the years 2005 and 2013. Literature review of the literature, conducted with the guiding question: What Brazilian scientific productions have been addressing about the training of nurses for Primary Care? The search was carried out with the descriptors "Curriculum" and "Education in Nursing", being identified 173 articles, of which 24 were selected. There were changes in nursing education, the nursing curriculum as a reflection of social dynamism, and the challenges to the implementation of the new curriculum. However, the committed role of the different actors allows the training of nurses consistent with the health needs of the population.

Keywords: Nursing; Curriculum; Higher education; Training of Human Resources.

\section{RESUMEN}

El desafío contemporáneo del sector educativo es formar a ciudadanos competentes en soluciones a situaciones cotidianas. El objetivo es analizar la producción científica brasileña en la formación de las enfermeras de atención primaria de salud, la base de datos Lilacs, entre 2005 y 2013. Revisión de la literatura, con la pregunta guía: ¿Qué producción científica brasileña vienen en la formación de enfermeras, direccionamiento para atención básica? Se llevó a cabo la búsqueda con las palabras clave "Resume" y "la educación en enfermería", siendo identificados los 173 artículos, de los cuales 24 fueron seleccionados. Ha habido movimientos de cambios en la formación de las enfermeras, el plan de estudios de enfermería como un reflejo del dinamismo social y desafíos para la implementación del nuevo currículo. Sin embargo, las acciones cometieron en los distintos actores permite la formación de la enfermera coherente con las necesidades de salud de la población.

Palabras clave: Enfermería; Curriculum; Educación Superior; Desarrollo de Personal.

\section{INTRODUÇÃO}

0 papel do ensino nas instituições foi se transformando, e a universidade foi e é constantemente solicitada a enfrentar novos desafios e mudanças. Atualmente, o papel do ensino nas universidades é buscar caminhos que consolidem projetos pedagógicos coerentes com as exigências impostas pelos avanços tecnológicos e científicos, ou seja, capacitar profissionais para cumprir os desafios da modernidade, sem perder de vista as perspectivas de uma educação/ensino que atenda às demandas sociais da população, possibilitando assim uma realidade mais igualitária e humana ${ }^{1}$.

0 exposto tende a indicar que constitui, como expõem Giovanella et al. ${ }^{2}$, desafio permanente, portanto, o reforço de uma robusta articulação entre as instituições formadoras e 0 serviço. Há que se corrigir o descompasso entre a orientação da formação dos profissionais de saúde e os princípios, as diretrizes e as necessidades do Sistema Único de Saúde (SUS), em especial no que diz respeito à formação para a atenção básica. Com tal fim, a Estratégia Saúde da Família (ESF) é tida como estratégia prioritária para o fortalecimento da Atenção Básica ${ }^{3}$.

Costa e Miranda ${ }^{4}$ abordam que o processo de implantação do SUS trouxe modificações para a organização das práticas de atenção e de gestão do sistema de saúde, mediante a formulação e ampliação de propostas de novos modelos assistenciais, envolvendo a diversificação dos serviços de saúde, os novos processos de qualificação dos trabalhadores e a natureza do trabalho em saúde. Assim, novos paradigmas devem nortear a formação dos trabalhadores da área.

Nesse contexto da educação superior, segundo o Ministério da Saúde, a flexibilização preconizada pela Lei de Diretrizes e Bases da Educação Nacional nº 9.394, de 20 de dezembro de 1996, confere às Instituições de Ensino Superior novos graus de liberdade que possibilitam o desenho de currículos inovadores, adequados às realidades regionais e às respectivas vocações das escolas. A ruptura do currículo mínimo pelas Diretrizes Curriculares Nacionais (DCN) representa um avanço, pelo fato de induzir maior articulação das Instituições Ensino Superior (IES) com a sociedade, e concretizar a relevância social da ação acadêmica. Na área da saúde, as DCN reforçam a necessidade de orientar a formação profissional para o trabalho no SUS ${ }^{5}$, sistema de saúde vigente no país, e orientado pela Atenção Básica.

Partindo desse pressuposto, surge, em 2005, por meio da Portaria Interministerial MS/MEC n² 2.101, o Pró-saúde, que objetivou incentivar a transformação do processo de formação, geração de conhecimento e prestação de serviços à população para abordagem integral do processo saúdedoença. Tem como eixo central a integração ensino-serviço, 
com a consequente inserção dos estudantes no cenário real de práticas que é a Rede SUS, com ênfase na atenção básica, desde o início de sua formação ${ }^{5}$.

Entendendo que a priorização da atenção básica, como direciona o SUS, não pode depender apenas de uma transformação espontânea das instituições acadêmicas, o papel indutor do Pró-Saúde é o de conferir direcionalidade ao processo de mudança e facilitar a consecução dos objetivos propostos, em busca de uma atenção à saúde mais equânime e de qualidade 5 .

Essa reorientação proposta pelo Pró-Saúde emerge de um momento em que a formação pretendida decorre de novas modalidades de organização do mundo do trabalho em saúde, e de exigências em relação ao perfil dos novos profissionais, confrontando diferentes culturas e linguagens que permitam ao aluno aprendizagens e práticas para uma formação sólida e integrada ${ }^{6}$.

Diante do exposto, este estudo objetiva analisar a produção científica brasileira sobre a formação do enfermeiro para Atenção Básica, entre os anos de 2005 e 2013.

\section{METODOLOGIA}

Revisão integrativa na qual se adotaram as seguintes etapas: seleção da pergunta de pesquisa; estabelecimento de critérios de inclusão e exclusão de artigos (seleção da amostra); definição das informações a serem extraídas dos artigos selecionados; análise dos resultados; discussão e apresentação dos resultados e a última etapa consistiu na apresentação da revisão.

Formulou-se a seguinte questão para guiar a revisão: 0 que as produções científicas brasileiras vêm abordando sobre a formação do enfermeiro para a Atenção Básica?

Realizou-se um recorte temporal, de 2005 a 2013, durante a busca na Base de Dado Lilacs. Isso porque se almeja construir o cenário da formação do enfermeiro para a Atenção Básica, entendendo a influência que este sofreu com a implantação do Programa Nacional de Reorientação da Formação Profissional (Pró-Saúde).

Para a seleção dos artigos utilizou-se uma base de dados nacional, o LILACS (Literatura Latino-Americana e do Caribe em Ciências da Saúde), esta que é referência em produção científica e técnica em saúde na América Latina e Caribe. Suas contribuições em registros bibliográficos vêm crescendo a cada ano sendo, em média, 25 mil registros ingressados anualmente.

Os critérios de inclusão dos artigos foram: artigos disponiveis eletronicamente; artigos nacionais; e artigos completos que abordam a formação do enfermeiro para a Atenção Básica. Foram excluídos: toda produção duplicada, editoriais, cartas ao editor, boletins epidemiológicos, bem como estudos que não abordem temática relevante ao alcance do objetivo da revisão.

A busca foi realizada pelo acesso on-line, utilizando 0 instrumento que contempla os seguintes itens: identificação do artigo original, características metodológicas do estudo, avaliação do rigor metodológico e dos resultados encontrados, dentre outras informações.

Os descritores utilizados foram "Currículo" e "Educação em Enfermagem" que foram cruzados utilizando o operador booleano and. Foram identificados 173 artigos, sendo que apenas 24 foram selecionados. 0s artigos foram lidos na integra e analisados quanto aos aspectos quantitativos e qualitativos. Em termos quantitativos, os dados foram analisados descritivamente em números absolutos, dispostos em quadros, compostos das seguintes variáveis: título; autores; ano; Estado; periódico; descritores; e tipo do estudo.

Em termos qualitativos, os indicadores foram recolhidos por meio da leitura exploratória, seletiva, analítica e interpretativa, tendo como premissas a formação do enfermeiro para a Atenção Básica.

\section{RESULTADOS}

A análise da produção científica sobre a formação do enfermeiro para a Atenção Básica ocorreu a partir da base de dados Lilacs. Foram encontrados 173 artigos por meio dos descritores utilizados na busca (currículo e educação em Enfermagem), sendo que, após serem aplicados os critérios de inclusão e exclusão adotados no estudo, foram selecionados 24 artigos. 0 Quadro 1 traz uma apresentação dos artigos selecionados na busca.

Quadro 1. Apresentação dos artigos selecionados na base de dados Lilacs (2005-2013). Sobral-CE: 2013.

\begin{tabular}{|c|c|c|c|c|c|c|c|}
\hline $\mathrm{N}^{0}$ & TÍTULO & AUTORES & ANO & ESTADO & PERIÓDICO & DESCRITORES & $\begin{array}{l}\text { TIPO DE } \\
\text { ESTUDO }\end{array}$ \\
\hline 01 & $\begin{array}{c}\text { Diretrizes curriculares } \\
\text { e estratégias para } \\
\text { implantação de } \\
\text { uma nova proposta } \\
\text { pedagógica }\end{array}$ & $\begin{array}{c}\text { Josicélia Dumêt } \\
\text { Fernandes, Iara de } \\
\text { Moraes Xavier, Maria } \\
\text { Isabel Pedreira de } \\
\text { Freitas Ceribelli, Maria } \\
\text { Helena Cappo Bianco, } \\
\text { Dirce Maeda, Michele V. } \\
\text { de C. Rodrigues }\end{array}$ & 2005 & Bahia & $\begin{array}{c}\text { Rev EsC } \\
\text { Enferm USP }\end{array}$ & $\begin{array}{l}\text { Currículo; } \\
\text { Enfermagem; } \\
\text { Educação em } \\
\text { Enfermagem; } \\
\text { Educação } \\
\text { baseada em } \\
\text { competências }\end{array}$ & $\begin{array}{l}\text { Estudo } \\
\text { teórico }\end{array}$ \\
\hline
\end{tabular}




\begin{tabular}{|c|c|c|c|c|c|c|c|}
\hline$N^{0}$ & TÍTULO & AUTORES & ANO & ESTADO & PERIÓDICO & DESCRITORES & $\begin{array}{l}\text { TIPO DE } \\
\text { ESTUDO } \\
\end{array}$ \\
\hline 02 & $\begin{array}{c}\text { A formação integral } \\
\text { dos profissionais de } \\
\text { saúde: possibilidades } \\
\text { para a humanização da } \\
\text { assistência }\end{array}$ & $\begin{array}{c}\text { Elizabeth Esperidião, } \\
\text { Denize Bouttelet } \\
\text { Munari }\end{array}$ & 2005 & Goiás & $\begin{array}{l}\text { Ciência, } \\
\text { Cuidado e } \\
\text { Saúde }\end{array}$ & $\begin{array}{l}\text { Educação; } \\
\text { Diretrizes } \\
\text { curriculares } \\
\text { nacionais; } \\
\text { Recursos } \\
\text { humanos; } \\
\text { Humanismo }\end{array}$ & $\begin{array}{l}\text { Estudo } \\
\text { teórico }\end{array}$ \\
\hline 03 & $\begin{array}{l}\text { Ensinar saúde/ } \\
\text { enfermagem numa } \\
\text { nova proposta de } \\
\text { reestruturação } \\
\text { acadêmica }\end{array}$ & $\begin{array}{l}\text { Josicélia Dumêt } \\
\text { Fernandes, Naomar de } \\
\text { Almeida Filho, Darci } \\
\text { de Oliveira Santa } \\
\text { Rosa, Márcia Pontes, } \\
\text { Neuranides Santana }\end{array}$ & 2005 & Bahia & $\begin{array}{c}\text { Rev EsC } \\
\text { Enferm USP }\end{array}$ & $\begin{array}{l}\text { Educação em } \\
\text { enfermagem; } \\
\text { Currículo; } \\
\text { Ensino }\end{array}$ & $\begin{array}{l}\text { Estudo } \\
\text { teórico }\end{array}$ \\
\hline 04 & $\begin{array}{l}\text { Participando da } \\
\text { construção de um } \\
\text { projeto pedagógico da } \\
\text { enfermagem }\end{array}$ & $\begin{array}{l}\text { Silvia Helena Zem- } \\
\text { Mascarenhas, Maria } \\
\text { Isabel Ruiz Beretta }\end{array}$ & 2005 & $\begin{array}{l}\text { São } \\
\text { Paulo }\end{array}$ & $\begin{array}{c}\text { Rev EsC } \\
\text { Enferm USP }\end{array}$ & $\begin{array}{l}\text { Currículo; } \\
\text { Enfermagem; } \\
\text { Educação em } \\
\text { Enfermagem; } \\
\text { Educação } \\
\text { baseada em } \\
\text { competências }\end{array}$ & $\begin{array}{l}\text { Estudo } \\
\text { teórico }\end{array}$ \\
\hline 05 & $\begin{array}{c}\text { A educação de } \\
\text { enfermagem: } \\
\text { buscando a formação } \\
\text { crítico-reflexiva e } \\
\text { as Competências } \\
\text { profissionais }\end{array}$ & $\begin{array}{l}\text { Kênia Lara Silva, } \\
\text { Roseni Rosângela de } \\
\text { Sena }\end{array}$ & 2006 & $\begin{array}{l}\text { Minas } \\
\text { Gerais }\end{array}$ & $\begin{array}{c}\text { Rev } \\
\text { Latino-am } \\
\text { Enfermagem }\end{array}$ & $\begin{array}{l}\text { Educação em } \\
\text { enfermagem; } \\
\text { Competência } \\
\text { profissional; } \\
\text { Aprendizagem } \\
\text { baseada em } \\
\text { problemas }\end{array}$ & Qualitativa \\
\hline 06 & $\begin{array}{l}\text { Currículo integrado: } \\
\text { analisando o } \\
\text { desempenho do } \\
\text { planejamento } \\
\text { participativo }\end{array}$ & $\begin{array}{c}\text { Maria Cristina Martinez } \\
\text { Capel Laluna, Clarice } \\
\text { Aparecida Ferraz }\end{array}$ & 2006 & $\begin{array}{l}\text { São } \\
\text { Paulo }\end{array}$ & $\begin{array}{c}\text { Rev Gaúcha } \\
\text { Enferm }\end{array}$ & $\begin{array}{l}\text { Educação em } \\
\text { enfermagem; } \\
\text { Currículo; } \\
\text { Planejamento } \\
\text { participativo }\end{array}$ & Qualitativa \\
\hline 07 & $\begin{array}{l}\text { Desenvolvimento } \\
\text { curricular do curso } \\
\text { de Enfermagem da } \\
\text { famema: contexto } \\
\text { atual }\end{array}$ & $\begin{array}{c}\text { Cássia Galli Hamamoto, } \\
\text { Maria José Sanches } \\
\text { Marin, Marília Simon } \\
\text { Sgambatti, Renata } \\
\text { Shimizu Locatelli da } \\
\text { Rosa, Silvia Franco da } \\
\text { Rocha Tonhom }\end{array}$ & 2006 & $\begin{array}{l}\text { São } \\
\text { Paulo }\end{array}$ & Rev Min Enf & $\begin{array}{l}\text { Educação em } \\
\text { Enfermagem; } \\
\text { Escolas de } \\
\text { Enfermagem; } \\
\text { Instituições } \\
\text { de Ensino } \\
\text { Superior; } \\
\text { Ensino/ } \\
\text { Métodos; } \\
\text { Currículo }\end{array}$ & $\begin{array}{l}\text { Relato de } \\
\text { Experiência }\end{array}$ \\
\hline 08 & $\begin{array}{c}0 \text { ensino de } \\
\text { enfermagem e as } \\
\text { diretrizes curriculares } \\
\text { nacionais: utopia } x \\
\text { realidade }\end{array}$ & $\begin{array}{c}\text { Elaine Emi Ito, Aida } \\
\text { Maris Peres, Regina } \\
\text { Toshie Takahashi, Maria } \\
\text { Madalena Januário } \\
\text { Leite }\end{array}$ & 2006 & $\begin{array}{l}\text { São } \\
\text { Paulo }\end{array}$ & $\begin{array}{c}\text { Rev EsC } \\
\text { Enferm USP }\end{array}$ & $\begin{array}{l}\text { Educação em } \\
\text { enfermagem/ } \\
\text { tendências; } \\
\text { Currículo; } \\
\text { Educação } \\
\text { baseada em } \\
\text { competências; } \\
\text { Mercado de } \\
\text { trabalho }\end{array}$ & $\begin{array}{l}\text { Revisão de } \\
\text { Literatura }\end{array}$ \\
\hline 09 & $\begin{array}{l}\text { Perfil de egresso de } \\
\text { Curso de Enfermagem } \\
\text { nas Diretrizes } \\
\text { Curriculares Nacionais: } \\
\text { uma aproximação }\end{array}$ & $\begin{array}{l}\text { Silvana Sidney Costa } \\
\text { Santos }\end{array}$ & 2006 & $\begin{array}{l}\text { Rio } \\
\text { Grande } \\
\text { do Sul }\end{array}$ & $\begin{array}{l}\text { Rev Bras } \\
\text { Enferm }\end{array}$ & $\begin{array}{l}\text { Educação em } \\
\text { enfermagem; } \\
\text { Currículo; } \\
\text { Enfermagem }\end{array}$ & $\begin{array}{c}\text { Revisão } \\
\text { Sistemática }\end{array}$ \\
\hline
\end{tabular}




\begin{tabular}{|c|c|c|c|c|c|c|c|}
\hline $\mathrm{N}^{0}$ & TÍTULO & AUTORES & ANO & ESTADO & PERIÓDICO & DESCRITORES & $\begin{array}{l}\text { TIPO DE } \\
\text { ESTUDO }\end{array}$ \\
\hline 10 & $\begin{array}{l}\text { Implementando } \\
\text { as unidades } \\
\text { educacionais do curso } \\
\text { de Enfermagem da } \\
\text { Famema: relato de } \\
\text { experiência }\end{array}$ & $\begin{array}{l}\text { Kátia Terezinha Alves } \\
\text { Rezende, Elisabete } \\
\text { Takeda, Elaine } \\
\text { Morelato Vilela Fraga, } \\
\text { Luzmarina A. Doreto } \\
\text { Braccialli, Mara Quaglio } \\
\text { Chirelli, Maria Cristina } \\
\text { Guimarães da Costa, } \\
\text { Maria Cristina Martinez } \\
\text { Capel Laluna, Maria } \\
\text { Elizabeth S. Hernandes } \\
\text { Correa, Sílvia Franco da } \\
\text { Rocha Tonhom }\end{array}$ & 2006 & $\begin{array}{l}\text { São } \\
\text { Paulo }\end{array}$ & $\begin{array}{l}\text { Interface } \\
\text { - Comunic, } \\
\text { Saúde, Educ }\end{array}$ & $\begin{array}{l}\text { Enfermagem; } \\
\text { Educação em } \\
\text { Enfermagem; } \\
\text { Currículo }\end{array}$ & $\begin{array}{l}\text { Relato de } \\
\text { Experiência }\end{array}$ \\
\hline 11 & $\begin{array}{c}\text { A formação do } \\
\text { enfermeiro: } \\
\text { contradições e } \\
\text { desafios à prática } \\
\text { pedagógica }\end{array}$ & $\begin{array}{l}\text { Joelma Batista Tebaldi } \\
\text { Pinto, Alda Muniz Pepe }\end{array}$ & 2007 & Bahia & $\begin{array}{c}\text { Rev Rev } \\
\text { Latino-am } \\
\text { Enfermagem }\end{array}$ & $\begin{array}{l}\text { Currículo; } \\
\text { Docentes; } \\
\text { Papel do } \\
\text { profissional de } \\
\text { enfermagem }\end{array}$ & $\begin{array}{l}\text { Quanti- } \\
\text { qualitativa }\end{array}$ \\
\hline 12 & $\begin{array}{l}\text { Desafios da formação } \\
\text { em enfermagem no } \\
\text { Brasil: proposta } \\
\text { curricular da EEUSP } \\
\text { para o bacharelado em } \\
\text { enfermagem }\end{array}$ & $\begin{array}{l}\text { Maria Amélia de } \\
\text { Campos Oliveira, } \\
\text { Maria De Lá Ó Ramallo } \\
\text { Veríssimo, Vilanice de } \\
\text { Araújo Püschel, Maria } \\
\text { Luiza Gonzalez Riesco }\end{array}$ & 2007 & $\begin{array}{c}\text { São } \\
\text { Paulo }\end{array}$ & $\begin{array}{c}\text { Rev Esc } \\
\text { Enferm USP }\end{array}$ & $\begin{array}{c}\text { Enfermagem; } \\
\text { Ensino; } \\
\text { Currículo }\end{array}$ & $\begin{array}{l}\text { Estudo } \\
\text { teórico }\end{array}$ \\
\hline 13 & $\begin{array}{l}\text { Integração curricular } \\
\text { na formação superior } \\
\text { em saúde: refletindo } \\
\text { sobre o processo de } \\
\text { mudança nos cursos do } \\
\text { Unifeso }\end{array}$ & $\begin{array}{c}\text { Verônica Santos } \\
\text { Albuquerque, Suzelaine } \\
\text { Tanji, } \\
\text { Carmen Maria dos } \\
\text { Santos Lopes Monteiro } \\
\text { Dantas da Silva, Edneia } \\
\text { Tayt-Sohn Martuchelli } \\
\text { Moço, Kátia Cristina } \\
\text { Felippe, José Feres } \\
\text { Abido Miranda }\end{array}$ & 2007 & $\begin{array}{l}\text { Rio de } \\
\text { Janeiro }\end{array}$ & $\begin{array}{l}\text { Rev Bras } \\
\text { Educ Médica }\end{array}$ & $\begin{array}{l}\text { Educação; } \\
\text { Saúde; } \\
\text { Currículo; } \\
\text { Prática } \\
\text { Profissional }\end{array}$ & $\begin{array}{l}\text { Relato de } \\
\text { Experiência }\end{array}$ \\
\hline 14 & $\begin{array}{l}\text { Reformas curriculares } \\
\text { no ensino de } \\
\text { graduação em } \\
\text { Enfermagem: } \\
\text { processos, tendências } \\
\text { e desafios }\end{array}$ & $\begin{array}{c}\text { Andressa Backes, } \\
\text { Rosiele Pinho Gonzaga } \\
\text { da Silva, Rosa Maria } \\
\text { Rodrigues }\end{array}$ & 2007 & Paraná & $\begin{array}{l}\text { Cienc Cuid } \\
\text { Saude }\end{array}$ & $\begin{array}{l}\text { Educação em } \\
\text { enfermagem; } \\
\text { Currículo; } \\
\text { Educação } \\
\text { superior }\end{array}$ & $\begin{array}{l}\text { Revisão } \\
\text { Sistemática }\end{array}$ \\
\hline 15 & $\begin{array}{c}\text { Formação profissional: } \\
\text { mudanças ocorridas } \\
\text { nos Cursos de } \\
\text { Enfermagem, CE, Brasil }\end{array}$ & $\begin{array}{c}\text { Silvia Maria Nóbrega } \\
\text { Therrien, Marcília } \\
\text { Chagas Barreto, } \\
\text { Maria Irismar de } \\
\text { Almeida, Thereza Maria } \\
\text { Magalhães Moreira }\end{array}$ & 2008 & Ceará & $\begin{array}{l}\text { Rev Bras } \\
\text { Enferm }\end{array}$ & $\begin{array}{c}\text { Educação; } \\
\text { Enfermagem; } \\
\text { Bacharelato } \\
\text { em } \\
\text { enfermagem }\end{array}$ & $\begin{array}{l}\text { Estudo } \\
\text { Teórico }\end{array}$ \\
\hline 16 & $\begin{array}{l}\text { Processo de formação } \\
\text { da(o) enfermeira(o) na } \\
\text { Contemporaneidade: } \\
\text { desafios e } \\
\text { perspectivas }\end{array}$ & $\begin{array}{c}\text { Mary Gomes Silva, } \\
\text { Josicelia Dumêt } \\
\text { Fernandes, Giselle } \\
\text { Alves da Silva Teixeira, } \\
\text { Rosana Maria de } \\
\text { Oliveira Silva }\end{array}$ & 2010 & Bahia & $\begin{array}{l}\text { Tex Cont } \\
\text { Enferm }\end{array}$ & $\begin{array}{l}\text { Currículo. } \\
\text { Ensino. } \\
\text { Educação. } \\
\text { Enfermagem }\end{array}$ & $\begin{array}{l}\text { Estudo } \\
\text { Teórico }\end{array}$ \\
\hline 17 & $\begin{array}{l}\text { Perspectivas do } \\
\text { ensino de bioética } \\
\text { na graduação em } \\
\text { enfermagem }\end{array}$ & $\begin{array}{l}\text { Juliana Dias Reis } \\
\text { Pessalacia, Valéria } \\
\text { Conceição de OliveiraI, } \\
\text { Heloíza Maria Siqueira } \\
\text { Rennó, Eliete Albano } \\
\text { de Azevedo Guimarães }\end{array}$ & 2011 & $\begin{array}{l}\text { Minas } \\
\text { Gerais }\end{array}$ & $\begin{array}{l}\text { Rev Bras } \\
\text { Enferm }\end{array}$ & $\begin{array}{c}\text { Ética; } \\
\text { Bioética; } \\
\text { Currículo; } \\
\text { Enfermagem }\end{array}$ & $\begin{array}{l}\text { Relato de } \\
\text { Experiência }\end{array}$ \\
\hline 18 & $\begin{array}{c}\text { Formação em } \\
\text { enfermagem: interface } \\
\text { entre as diretrizes } \\
\text { curriculares e os } \\
\text { conteúdos de atenção } \\
\text { básica }\end{array}$ & $\begin{array}{c}\text { Maria Josefina Silva, } \\
\text { Eliane Miranda de } \\
\text { Sousa, Cibelly Lima } \\
\text { Freitas }\end{array}$ & 2011 & Ceará & $\begin{array}{l}\text { Rev Bras } \\
\text { Enferm }\end{array}$ & $\begin{array}{l}\text { Enfermagem; } \\
\text { Atenção } \\
\text { Primária à } \\
\text { Saúde; Ensino }\end{array}$ & $\begin{array}{c}\text { Estudo } \\
\text { Documental }\end{array}$ \\
\hline
\end{tabular}




\begin{tabular}{|c|c|c|c|c|c|c|c|}
\hline $\mathrm{N}^{0}$ & TÍTULO & AUTORES & ANO & ESTADO & PERIÓDICO & DESCRITORES & $\begin{array}{l}\text { TIPO DE } \\
\text { ESTUDO } \\
\end{array}$ \\
\hline 19 & $\begin{array}{l}\text { Unidade teórico- } \\
\text { prática na práxis } \\
\text { de um currículo } \\
\text { integrado: percepção } \\
\text { de docentes de } \\
\text { Enfermagem na saúde } \\
\text { da criança e do } \\
\text { adolescente }\end{array}$ & $\begin{array}{c}\text { Maisa Tavares de Souza } \\
\text { Leite, Conceição Vieira } \\
\text { da Silva Ohara, Tereza } \\
\text { Yoshiko Kakehashi, } \\
\text { Circéa Amália Ribeiro }\end{array}$ & 2011 & $\begin{array}{l}\text { Minas } \\
\text { Gerais }\end{array}$ & $\begin{array}{l}\text { Rev Bras } \\
\text { Enferm }\end{array}$ & $\begin{array}{l}\text { Educacao em } \\
\text { enfermagem; } \\
\text { Curriculo; } \\
\text { Saude da } \\
\text { crianca; } \\
\text { Saude do } \\
\text { adolescente; } \\
\text { Pesquisa } \\
\text { qualitativa }\end{array}$ & Qualitativo \\
\hline 20 & $\begin{array}{l}\text { Resolução de } \\
\text { problemas no contexto } \\
\text { de currículo } \\
\text { Integrado de } \\
\text { enfermagem }\end{array}$ & $\begin{array}{c}\text { Elaine Alves, Neusi } \\
\text { Aparecida Navas Berbel }\end{array}$ & 2012 & Paraná & $\begin{array}{c}\text { Cienc Cuid } \\
\text { Saude }\end{array}$ & $\begin{array}{l}\text { Educação; } \\
\text { Enfermagem; } \\
\text { Resolução de } \\
\text { Problemas }\end{array}$ & Qualitativo \\
\hline 21 & $\begin{array}{c}\text { Identificação dos } \\
\text { pilares da educação } \\
\text { na disciplina } \\
\text { integralidade no } \\
\text { cuidado à saúde }\end{array}$ & $\begin{array}{c}\text { Zeyne Alves Pires } \\
\text { Scherer, Edson Arthur } \\
\text { Scherer }\end{array}$ & 2012 & $\begin{array}{l}\text { São } \\
\text { Paulo }\end{array}$ & $\begin{array}{c}\text { Rev Esc } \\
\text { Enferm USP }\end{array}$ & $\begin{array}{l}\text { Educação em } \\
\text { enfermagem; } \\
\text { Educação } \\
\text { superior } \\
\text { Estudantes de } \\
\text { enfermagem; } \\
\text { Currículo; } \\
\text { Assistência } \\
\text { Integral à } \\
\text { Saúde }\end{array}$ & $\begin{array}{l}\text { Estudo } \\
\text { Teórico }\end{array}$ \\
\hline 22 & $\begin{array}{l}0 \text { desenvolvimento } \\
\text { de competências no } \\
\text { curso de graduação } \\
\text { em Enfermagem: } \\
\text { percepção de egressos }\end{array}$ & $\begin{array}{l}\text { Sarah Nancy Deggau } \\
\text { Hegeto de Souza, Ana } \\
\text { Maria Kazue Miyadahira }\end{array}$ & 2012 & Paraná & $\begin{array}{l}\text { Cienc Cuid } \\
\text { Saude }\end{array}$ & $\begin{array}{l}\text { Educação em } \\
\text { Enfermagem; } \\
\text { Currículo; } \\
\text { Estudantes de } \\
\text { Enfermagem; } \\
\text { Competência } \\
\text { Profissional; } \\
\text { Prática } \\
\text { Profissional }\end{array}$ & Quantitativo \\
\hline 23 & $\begin{array}{l}0 \text { olhar do aluno } \\
\text { habitando um } \\
\text { currículo integrado } \\
\text { de Enfermagem: uma } \\
\text { análise existencial }\end{array}$ & $\begin{array}{c}\text { Mara Lúcia Garanhani, } \\
\text { Elizabeth Ranier } \\
\text { Martins do Valle }\end{array}$ & 2012 & Paraná & $\begin{array}{l}\text { Cienc Cuid } \\
\text { Saude }\end{array}$ & $\begin{array}{l}\text { Educação em } \\
\text { Enfermagem; } \\
\text { Currículo; } \\
\text { Pesquisa } \\
\text { Qualitativa }\end{array}$ & Qualitativo \\
\hline 24 & $\begin{array}{c}\text { Aderência de curso } \\
\text { de graduação em } \\
\text { Enfermagem às } \\
\text { Diretrizes Curriculares } \\
\text { Nacionais na } \\
\text { perspectiva do Sistema } \\
\text { Único de Saúde }\end{array}$ & $\begin{array}{c}\text { Josicelia Dumêt } \\
\text { Fernandes; Rosana } \\
\text { Maria de Oliveira Silva; } \\
\text { Giselle Alves Teixeira; } \\
\text { Raissa Millena Silva } \\
\text { Florencio; Lázaro Souza } \\
\text { da Silva; Lyra Cândida } \\
\text { Calhau Rebouças }\end{array}$ & 2013 & Bahia & $\begin{array}{l}\text { Rev Esc Anna } \\
\text { Nery }\end{array}$ & $\begin{array}{l}\text { Educação em } \\
\text { Enfermagem. } \\
\text { Currículo. } \\
\text { Sistema Único } \\
\text { de Saúde }\end{array}$ & Qualitativo \\
\hline
\end{tabular}

Fonte: elaborado pelos autores.

Alguns pontos presentes na apresentação dos artigos merecem ser discutidos. Com relação à distribuição temporal dos artigos selecionados no estudo, observa-se que apenas no ano de 2009 não ocorreram produções científicas voltadas à formação do enfermeiro, inferindo o envolvimento deste cada vez maior com a pesquisa. Oliveira, Haddad e Bortoletto ${ }^{7}$ enfatizam que a produção científica em Enfermagem cresce a cada ano constituindo-se em um meio de disseminação em que alunos e profissionais ampliam as fronteiras do conhecimento. Cabe destacar que se entende por pesquisa como uma atividade intelectual e um labor que resulta da relação do homem com o mundo como um observador, indagador e interventor.

Ressalta-se ainda a distribuição geográfica das publicações brasileiras, em que as Regiões que mais concentram as publicações são o Sudeste e o Sul, com 11 e seis artigos, respectivamente; ficando o Nordeste com cinco artigos, o Centro-0este com um, e a Região Norte sem nenhuma publicação identificada nesta revisão. Nesse contexto, pode-se falar que as publicações apresentam em assimetrias entre regiões, entre instituições na própria região, nas mesorregiões ou nos estados e entre áreas de conhecimento ${ }^{8}$; isso pode ser um reflexo das assimetrias já existentes entre os Sistemas de Pós-Graduação no Brasil.

Com relação aos descritores, os artigos selecionados demonstraram o cuidado na pesquisa científica ao manter um vocábulo 
coerente com o objeto de estudo, aspecto que é primordial na disseminação das tendências relacionadas em cada artigo. 0s Descritores em Ciências da Saúde (DeCS) foram criados para servir como uma linguagem única na indexação de artigos de revistas científicas, livros, anais de congressos, relatórios técnicos, e outros tipos de materiais, assim como para ser usado na pesquisa e recuperação de assuntos da literatura científica nas fontes de informação disponíveis na Biblioteca Virtual em Saúde-BVS 9 .

Os artigos selecionados foram examinados criteriosamente, culminando na formação de categorias, que se basearam no foco principal de cada estudo, para análise e discussão, a saber: "Diretrizes Curriculares Nacionais e Diretrizes Curriculares do Curso de Graduação em Enfermagem: os movimentos de mudança e seus desafios", "Currículo e seus novos contextos: a formação do enfermeiro sob influência da dinamicidade social", e "O desafio da implantação do currículo integrado".

Diretrizes Curriculares Nacionais e Diretrizes Curriculares do Curso de Graduação em Enfermagem: os movimentos de mudança e seus desafios

No que se refere às mudanças nos Cursos de Enfermagem promovidas pelas Diretrizes Curriculares Nacionais (DCN) e as Diretrizes Curriculares Nacionais do Curso de Graduação em Enfermagem (DCEnf), cinco artigos contemplam tais aspectos.

De acordo com Fernandes et al. ${ }^{10}$, as mudanças crescentes no mundo globalizado e seu acelerado processo de modernização científica e tecnológica vêm exigindo novas e contextualizadas ações que incrementem a implementação de políticas públicas com expressões concretas nas áreas sociais, particularmente na saúde e educação. Esse aspecto de direcionalidade social imprimido a formação do enfermeiro apresenta a DCN e as DCEnf como dispositivos para a reestruturação dos cursos de graduação em Enfermagem, cabendo aqui ainda mencionar a Lei de Diretrizes e Bases da Educação Nacional (LDB); esta, segundo os mesmos autores, fundamenta o processo de formação da educação superior.

Assim, as mudanças curriculares, no ensino de enfermagem no Brasil, tiveram historicamente a preocupação com a adequação da formação do enfermeiro aos interesses do mercado de trabalho. Entretanto, o desafio na formação precisa transpor o foco desses interesses e inserir efetivamente o futuro enfermeiro no sistema de saúde, comprometido com as transformações exigidas pelo exercício da cidadania, como discute um dos artigos do estudo.

As DCEnf explicitam a necessidade do compromisso com os princípios da Reforma Sanitária, com ênfase no SUS, ao

\section{A mudança das instituições formadoras só faz sentido se for para a qualificação do SUS.}

passo que definem os princípios básicos para a formação de profissionais críticos, reflexivos, inseridos no contexto histórico-social, pautados em princípios éticos e capazes de intervirem nos problemas/situações da atenção à saúde ${ }^{11}$. Isso vai ao encontro do discutido em um dos artigos desta revisão, no qual aborda que o movimento para a formação de recursos humanos para a saúde deve ser fundamentado no referencial ético-humanístico.

Este mesmo artigo traz a reflexão sobre o distanciamento existente entre instituições formadoras e o SUS, configurandose em um desafio a ser superado. Siqueira-Batista et al. ${ }^{12}$ refletem que ampliar - e rediscutir - o papel das instituições de ensino superior é fundamental nesse processo. Transformar a formação e a atenção à saúde são movimentos simultâneos e complementares. A mudança das instituições formadoras só faz sentido se for para a qualificação do SUS, reconhecendose que existem movimentos localizados, os quais precisam ser ampliados e integrados, para que alcancem resultados efetivos no conjunto do cuidado à saúde. Neste contexto, os currículos por competências têm sido divisados como boas alternativas para a implantação das transformações consideradas seminais para a nova lógica de formação dos profissionais de saúde.

Isso é corroborado por um dos artigos, uma vez que ele traz algumas reflexões conceituais e metodológicas que possam direcionar a mudança no processo de formação de enfermeiros, além de apontar estratégias para a implantação da nova proposta pedagógica, baseando-se no desafio da implementação das DCEnf. Outro artigo centraliza-se no papel importante desempenhado pela $D C N$, ressaltando que esta não veio só estabelecer novos marcos e objetivos para a formação do enfermeiro, mas sim realizar um trabalho coletivo para o crescimento da categoria.

Mediante esse pluralismo observado na sociedade atual e a complexidade dos problemas de saúde, além da sofisticação crescente imposta pela tecnologia, o sistema educacional precisa repensar sua função como formador de profissionais que irão atuar nessa mesma sociedade. Eles estarão envolvidos com questões de ordem técnica, científica, social e ética, e é esperado que estejam preparados para articular seus conhecimentos quando precisarem tomar decisões ${ }^{13}$. 
Currículo e seus novos contextos: a formação do enfermeiro sob influência da dinamicidade social

Essa categoria aborda aspectos relacionados ao currículo de instituições de ensino cenários dos artigos desta revisão, em especial os processos de mudanças e de adaptação imprimidos pelo currículo integrado na formação. Um artigo retrata a necessidade de construção de uma universidade renovada no que concerne à formação do enfermeiro, favorecendo o desenvolvimento de práticas educativas mais aderentes aos contextos de vida e à pluralidade e singularidade dos processos sociais concretos.

Para tal, surge a proposta do currículo integrado como um esforço na busca da articulação teoria e prática sem fragmentação, como menciona outro artigo, que ao se realizar um diálogo interno com os demais artigos dessa categoria, faz-se a alusão justificatória da necessidade inovadora do currículo integrado: a compreensão da formação do enfermeiro como um processo contínuo, no qual se considera a dinamicidade da sociedade e dos serviços de saúde. Entende-se aqui que a reflexão de uma prática profissional e a viabilidade das transformações incitadas pelo novo currículo se constitui no principal desafio para a concretude do mesmo.

Para Albuquerque et al. ${ }^{14}$ o currículo integrado valoriza o espaço de articulação entre ensino, serviço e comunidade como cenário do processo ensino-aprendizagem, devendo o estudante refletir sobre sua ação e a realidade em que está inserido, buscando problematizar o seu cotidiano, tomando o que tem para ser aprendido como mola propulsora do processo de formação, na perspectiva de uma aprendizagem crítica e reflexiva.

Um artigo enfatiza bem o processo de reorientação curricular na formação de profissionais para atuar na Atenção Básica, sob a influência das DCN e das DCEnf, em que um currículo mais voltado para os princípios da Atenção Básica, juntamente com a proposta da integralidade curricular, potencializa as discussões na área da educação ao ponderar a formação para o SUS. Para isso, faz-se necessário repensar estratégias adotadas na prática pedagógica, de modo a integrar mais veementemente teoria e prática, como sinaliza outro artigo.

Entretanto, esses passos foram dados com mínima articulação entre os Ministérios da Educação e da Saúde. Embora o SUS tenha responsabilidade constituída na formação de profissionais na área da saúde, o que se observa é uma insuficiência de orientações e ações no processo de formação e, quando ocorrem voltam-se para formação e capacitação de profissionais já graduados, no sentido de suprimir deficiências do serviço, especialmente na atenção

\section{...serviços de \\ saúde como locais de ensino- aprendizagem...}

básica ${ }^{15}$. Esta desarticulação aponta para uma lacuna desde a implantação do SUS, quanto à formação do profissional para o SUS, uma vez que os Ministérios agiram de forma fragmentada e pontual a partir da Reforma Sanitária e, somente em 2005 houve uma significativa cooperação técnica interministerial por meio do Pró-Saúde 5 .

0 Pró-Saúde visa aproximar a academia com os serviços públicos de saúde, como um dos mecanismos fundamentais para transformar o aprendizado, com base na realidade sócio-econômica e sanitária brasileira. Esta iniciativa estreita as relações da graduação em saúde no país com as equipes de saúde que estão na ponta do atendimento. Coloca os serviços de saúde como locais de ensino-aprendizagem que expressam a indissociabilidade entre a assistência, a gestão e a formação em saúde ${ }^{5}$. Inicialmente, o Pró-Saúde orientou a formação nos cursos de medicina, odontologia e enfermagem, compreendendo estes profissionais como os compositores da essência na atenção básica, porém, hoje as demais profissões na saúde também são objetos do programa, em uma lógica de transdisciplinaridade.

Articular saberes, dentro dos diversos cenários de aprendizagem, proposto pelo SUS, é contemplar o engendramento do ensino-serviço, teoria-prática e açãoreflexão-ação, na educação e orientação da formação do enfermeiro para atuar na integralidade da atenção à saúde, na construção de vínculos nas relações entre profissionais e usuários na superação do modelo centralizador persistente (existente) até os dias atuais. Esta visão de inter e transdisciplinaridade nos serviços de saúde é outro grande desafio a ser considerado ${ }^{15,16}$.

\section{0 desafio da implantação do currículo integrado}

A análise criteriosa dos artigos selecionados nessa revisão elucidou alguns desafios imprimidos pela implantação do novo currículo com base nas DCN. Tecem-se aqui linhas nas quais repousam estes desafios da integração, conforme verificados nos artigos.

Um artigo menciona o movimento de transformação das estruturas acadêmicas, redimensionando a posição 
do estudante como um sujeito ativo no processo ensino aprendizagem, estimulando a participação política e crítica dos alunos. Um dos desafios para os atores envolvidos no SUS e Instituições de Ensino Superior (IES) é a formação de profissionais de saúde competentes diante das situações reais, postas pelos serviços e pela gestão em saúde. Então, se há preocupação com a efetivação do SUS, há, necessariamente, que se voltar para o 'como' e 'para quê' formam-se os enfermeiros ${ }^{17}$.

Contudo, existem dificuldades a serem enfrentadas, uma vez que todo processo de mudança traz aspectos de incertezas. Isso é verificado em outro artigo, que retrata a dificuldade dos professores e alunos em conceituar currículo, sendo que este se caracteriza como do tipo coleção, com uma prática pedagógica voltada, predominantemente, para o modelo tradicional, direcionando a formação do enfermeiro ainda em uma lógica biomédica-tecnicista. Nóbrega-Therrien, e Feitosa ${ }^{18}$ discorrem que as mudanças no ensino superior se tornarão viáveis e aceleradas se os educadores reformularem sua visão do processo de ensino e de aprendizagem, dando ênfase ao desenvolvimento efetivo do espírito crítico.

Destaca-se que a garantia de uma formação integral do enfermeiro implica o aprofundamento necessário do conhecimento em sua dimensão científica e histórica, compartilhada em experiências com práticas coletivas, que abranjam a dimensão de cidadania, a fim de superar definitivamente a prática profissional instrumentadora, tecnicista e acrítica ${ }^{19}$.

Com relação aos desafios e perspectivas na reorientação do processo de formação do enfermeiro, um artigo enfatiza a resistência às mudanças, a pouca reflexão sobre a docência, 0 distanciamento dos serviços de saúde, o que gera um reforço à clássica dicotomia entre o pensar e o fazer. Isso apresenta outro fator complexo, os discentes sentem-se, por vezes, inseguros com a nova proposta pedagógica, como menciona outro artigo.

É preciso investir na sensibilização dos atores inseridos nos cenários onde se desenvolvem os cuidados e o processo de ensino-aprendizagem. Operacionalmente, a universidade deve se preocupar em identificar necessidades dos serviços e cenários de prática, estabelecendo pactos de contribuição docente/discente para tais serviços. Devem estar incluídos nestes pactos: negociação de espaços, horários e tecnologias para adequação das atividades do serviço e das práticas educacionais. Além disso, em contrapartida, é fundamental a participação de profissionais dos serviços e usuários nas discussões educacionais de formação na área da saúde ${ }^{14}$.

Verifica-se, então, a necessidade de um movimento de mudança sinérgico, em que a integração ensino-serviço aconteça efetivamente como resultado de um trabalho coletivo, pactuado e integrado de estudantes e professores

\section{...necessidade de um movimento de mudança sinérgico, em que a integração ensino- serviço aconteça efetivamente...}

dos cursos de formação na área da saúde com trabalhadores que compõem as equipes dos serviços de saúde, visando à qualidade da atenção à saúde individual e coletiva, à qualidade da formação profissional e ao desenvolvimento/ satisfação dos trabalhadores dos serviços ${ }^{14}$.

\section{CONCLUSÃO}

Partindo do objetivo de analisar a produção científica brasileira sobre a formação do enfermeiro para a Atenção Básica. Na qual se obtiveram 24 artigos, verificou-se que estes apresentam descritores coerentes com seus respectivos objetos de análise, além de uma concentração das publicações em algumas regiões do País, o que pode reverberar de um sistema de pós-graduação também assimétrico. Somente o ano de 2009 não apresentou publicação sobre a temática selecionada para este estudo de revisão.

Com relação aos movimentos de mudança instigados pelas DCN e DCEnf, verifica-se que estas atuam como dispositivos para a reestruturação dos cursos de graduação em Enfermagem, na perspectiva da direcionalidade social imprimido a formação do enfermeiro, cabendo a proposta de novos currículos para a reorientação da formação crítica e reflexiva.

Entende-se que toda mudança traz a estranheza e incerteza do novo, mas a atuação compromissada dos diversos atores envolvidos na implantação do novo currículo possibilita um resultado mais efetivo, que se traduz na qualidade da formação profissional e, consequentemente, satisfação dos usuários do SUS por terem um sistema de saúde mais resolutivo.

Mesmo com o objetivo desse estudo tencionando para a formação do enfermeiro para atuar na Atenção Básica, percebeu-se que não se conseguiu alcançá-lo tão plenamente, uma vez que poucos artigos trabalham a formação para a Atenção Básica. Muitos trazem a discussão da mudança curricular, dos desafios da implantação do currículo integrado. Assim, sugere-se a realização de mais estudos com o enfoque Atenção Básica, uma vez que esta se configura a essência do SUS. 


\section{CONTRIBUIÇÃO DOS AUTORES}

Maria da Conceição Coelho Brito contribuiu com 0 delineamento, realização da pesquisa, redação do manuscrito e revisão final. Fiama Kécia Silveira Teófilo contribuiu com o delineamento, realização da pesquisa e a redação do manuscrito. Maria Socorro de Araújo Dias contribuiu com o delineamento e revisão crítica do manuscrito. Maristela Inês Osawa Vasconcelos, Izabelle Mont'Alverne Napoleão Albuquerque e Lielma Carla Chagas da Silva contribuíram na revisão crítica do manuscrito.

\section{REFERÊNCIAS}

1. Opitz SP et al. 0 currículo integrado na graduação em enfermagem: entre 0 ethos tradicional e 0 de ruptura. Rev Gaúcha Enferm [internet]. 2008 [cited 2013 Apr 21]; 29(2). Available from: http://seer.ufrgs.br/ RevistaGauchadeEnfermagem/article/view/5598

2. Giovanella $L$ et al. Saúde da família: limites e possibilidades para uma abordagem integral de atenção primária à saúde no Brasil. Ciência \& Saúde Coletiva, 2009; 14(3).

3. Brasil. Ministério da Educação. A aderência dos cursos de graduação em enfermagem, medicina e odontologia às diretrizes curriculares nacionais [document on the internet] 2006. Brasília: Ministério da Saúde/Ministério da Educação. [cited 2013 Jun 10]. Available from: http://abeno.org.br/ arquivos/downloads/download_20111215103241.pdf

4. Costa RKS, Miranda FAN. Formação Profissional no SUS: oportunidades de mudanças na perspectiva da estratégia de saúde da família. Trab Educ Saúde, 2009; 6(3).

5. Brasil. Ministério da Saúde. Programa Nacional de Reorientação da Formação Profissional em Saúde - Pró-Saúde: objetivos, implementação e desenvolvimento potencial. Brasília: Ministério da Saúde, 2007. 86 p.

6. Kaiser DE, Serbim AK. Diretrizes curriculares nacionais: percepções de acadêmicos sobre a sua formação em enfermagem. Rev. Gaúcha Enferm [internet]. 2009 [cited 2013 Jun 10]; 30(4). Available from: http://www.scielo.br/ pdf/rgenf/v30n4/a08v30n4.pdf

7. Oliveira TS, Haddad MCL, Bortoletto MSS. Produção científica de graduandos em enfermagem publicada de 1995 a 2008. Rev. Espaço para a Saúde, 2010; 11(2): 21-8.

8. Brasil. Ministério da Educação. Coordenação de Aperfeiçoamento de Pessoal de Nível Superior Plano Nacional de Pós-Graduação - PNPG 2011-2020. Brasília, DF: CAPES, 2010.

9. Brasil. Biblioteca Virtual em Saúde. Decs - Descritores em Ciências da Saúde. Brasília: Biblioteca Virtual em Saúde, 2013 [home-page on the internet]. [cited 2013 Mai 20]. Available from: http://decs.bvs.br/P/decsweb2013.htm
10. Fernandes JD et al. Ensino da enfermagem psiquiátrica/ saúde mental: sua interface com a reforma psiquiátrica e diretrizes curriculares nacionais. Rev EsC Enferm USP, 2009; $43(4)$.

11. Brasil. Ministério da Educação. Conselho Nacional de Educação. Resolução CNE/CES n. 3, de 7 de novembro de 2001. Diretrizes Curriculares do Curso de Graduação em Enfermagem. Brasília, 2001.

12. Siqueira-Batista $R$ et al. Educação e competências para - SUS: é possivel pensar alternativas à(s) lógica(s) do capitalismo tardio? Cienc \& Saude Coletiva, 2013; 18(1): 159-710.

13. Erdmann AL et al. 0 olhar dos estudantes sobre sua formação profissional para a Sistema Único de Saúde. Acta paulista Enferm., 2009; 22(3).

14. Albuquerque VS et al. A integração ensino-serviço no contexto dos processos de mudança na formação superior dos profissionais da saúde. Rev Bras Educ Médica, 2008; 32(3).

15. Almeida LPG, Ferraz CA. Políticas de formação de recursos humanos em saúde e enfermagem. Rev Bras Enferm, 2008; 61(1):31-5.

16. Silva KL, Sena RR. Integralidade do cuidado na saúde: indicações a partir da formação do enfermeiro. Rev Esc Enferm USP, 2008; 42(1): 48-56.

17. Lucchese R, Vera I, Pereira WR. As políticas públicas de saúde - SUS - como referência para o processo ensinoaprendizagem do enfermeiro. Rev. Eletr. Enf [internet]. 2010 [cited 2013 Jun 12]; 12(3): 562-6. 2010. Available from: http://dx.doi.org/10.5216/ree.v12i3.11144

18. Nóbrega-Therrien SM, Feitosa LM. Ação formativa e o desafio para a graduação em saúde. Rev Bras Educ Médica, $2010 ; 34(2)$.

19. Scorzoni MF, Bueno SMV, Coscrato G. 0 currículo e as implicações dos novos paradigmas educacionais na formação do enfermeiro. Sau. \& Transf. Soc., 2013; 4(1).

Recebido em 11/04/2017 Aprovado em 09/09/2017

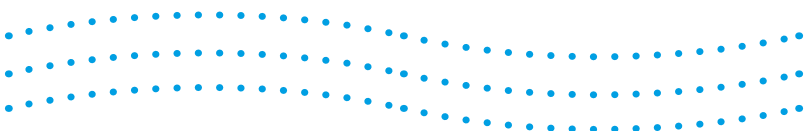

